\title{
A Case Of Intermediate Toxic Epidermal Necrolysis (Lyell Syndrome) Induced By Hydroxychloroquine Sulfate: A Report
}

\author{
Salissou Laouali (Dermatologist Venereologist) \\ National Hospital of Niamey and Medical School of Abdou Moumouni \\ University, Niamey/ Niger, Head of Dermatology and venerology Unit \\ Koudoukpo Christiane (Dermatologist Venereologist) \\ Medical School, Cotonou University, Cotonou/ Benin \\ Zaki Harouna (Histopathologist) \\ Laboratory of histopathology of Medical School \\ of Abdou Moumouni University, Niamey/Niger \\ Brah M Souleymane (Internal Medecin) \\ National Hospital of Niamey and Medical School \\ of Abdou Moumouni University, Niamey/ Niger \\ Nouhou Hassan (Histopathologist) \\ Professor of Histopathology, Laboratory of histopathology of Medical \\ School of Abdou Moumouni University, Niamey/ Niger
}

doi: 10.19044/esj.2016.v12n12p90 URL:http://dx.doi.org/10.19044/esj.2016.v12n12p90

\begin{abstract}
Malaria is a parasite disease that is endemic in tropical country as Niger (West Africa). Hydroxychloroquine sulfate (HCQ) is a synthetic antimalarial drug that is very often used to treat connective tissue diseases such as, scleroderma, systemic or discoid lupus erythematosus, rheumatoid arthritis. This drug may induce numerous cutaneous adverse reactions as well as the other anti-malarial drugs. We report on a case of intermediate Lyell syndrome that occurred in the first week of treatment of malaria attack with a young woman, aged 19, following the administration of hydroxychloroquine sulfate.
\end{abstract}

Keywords: Hydroxychloroquine sulfate, intermediate Lyell syndrome, malaria

\section{Introduction}

Lyell syndrome is a form of toxic epidermal necrolysis (TEN) that can be induced by certain drugs (Roujeau et al., 1995; Bechot et al., 2000; 
Bernard et al., 2010). It is well known that any drug can cause an adverse reaction that can occur from a few days to several weeks, during or after administration (Bernard et al., 2010; Studer et al., 2012). HCQ is a synthetic antimalarial drug rarely known to induce toxidermia of the TEN type. We report on a case of intermediate Lyell's syndrome induced by hydroxychloroquine sulfate in a young woman, aged 19, during a malaria treatment.

\section{Observation}

The patient, a 19-year-old young woman, presented a dorsolumbar epidermal detachment. Under questioning, she declared that the detachment was preceded by a generalized but intense pruritus in the same area. She also disclosed having taken hydroxychloroquine sulfate alone for the treatment of a malaria, following a positive blood smears test. In the first week of treatment, a generalized pruritus occurred, followed by the appearance of purplish blotches at the upper dorsal area and traveling down the lumbar spine. The epidermal detachment proper followed within 48 hours. A physical examination of the patient revealed a more extensive dorsolumbar epidermal peel off at the dorsal area stretching to the lumbar spine and exposing the underlying dermis (Figure 1). The lesion was very painful, moist and slightly purulent. A Nikolsky sign check turned out negative on the rest of the body. There was also a related small skin detachment on the posterior side of the middle third area of the right arm. All mucosas were free of lesions. An anatomopathological analysis of a biopsy sample from the dorsal surface of the right arm evidenced the conventional attacks: epidermal necrolysis with a dermal inflammatory infiltrate containing lymphocytes and red cells in bullous lesion (Figure2). Biologically, we noted no anomalies (especially with the liver or kidneys), except an hyperleukocytosis (12300) that mostly involved polynuclear neutrophils (70\%). Local care was prescribed with an antibiotic cover (macrolide) after excluding the possibility of their involvement. During a two-week follow up, we noticed that the epidermization was going on normally (Figure 3A, 2B); however, we lost sight of the patient after this period.

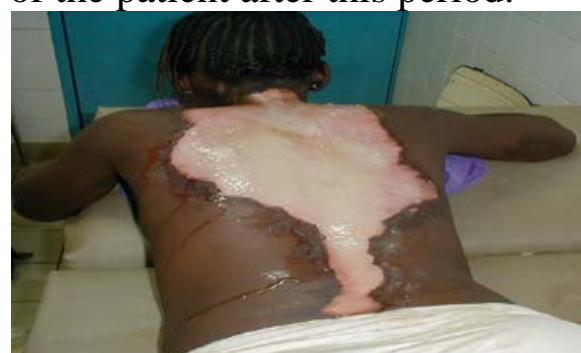

Figure 1: Epidermal detachment at the dorsolumbar area, with an onset of super infection,

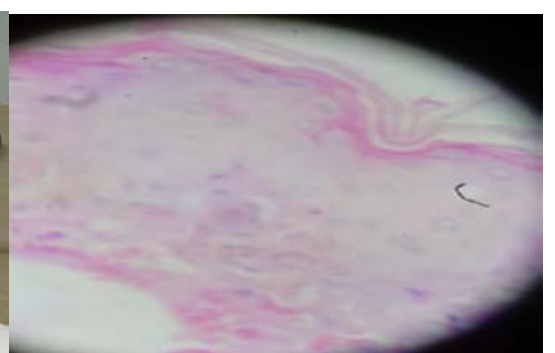

Figure2 Fig3: X100 Distinct epidermal necrolysis, with a dermal inflammatory infiltrate dermal containing lymphocytes and red cells. 


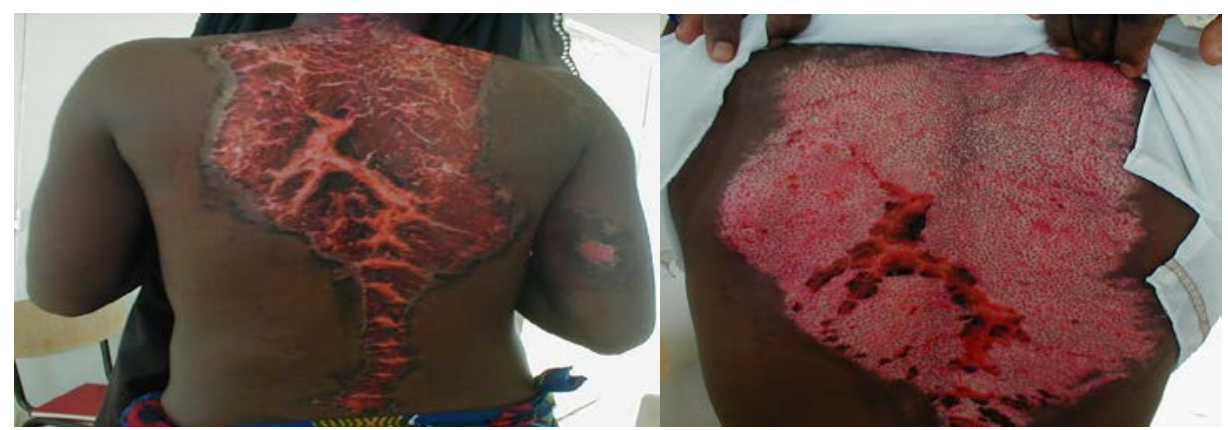

A: One week after treatment

B: Two weeks after treatment Fig3(A and B): Drying and epidermization of the skin at the dorsolumbar area and the right arm's posterior side.

\section{Discussion}

TEN is a drug-induced bullous toxidermia that destroys the skin and the mucosas (Lebrun-Vignes et al., 2015). The method of Begaud et al (Begaud et al., 1985), used to determine the source of unexpected or toxic effects of drugs, most often allows the identification of the drug causing the ailment. In our case, the identification of the drug in question was not difficult, since HCQ was the only molecule taken by the patient for her malaria treatment. Generally, as is true in our case, TEN occurs 1 to 4 weeks after the administration of the drug (Lebrun-Vignes et al., 2015). HCQ is a synthetic antimalarial drug whose side effects, as reported by various authors, are: Severe Acute Generalized Exanthematous Pustulosis (AGEP) (Naziha et al., 2010; Assier-Bonnet et al., 1996; Park et al., 2010), photoinduced toxidermia (Metayer et al., 2001), Drug Rash with Eosinophilia and Systemic Symptoms (DRESS) (Schmutz et al., 2008), and TEN (Plaquenil (hydroxychloroquine sulphate) tablets; 2006). Cases of Lyell syndrome are rare. Based on the size of the affected area, various types of TEN are distinguished: The Stevens Johnson syndrome (affected area is less than 10\% of body surface), the overlapping or intermediate Lyell syndrome (affected area between 10 and 30\%), and the full Lyell syndrome (affected area above 30\%) (Roujeau et al., 1995; Parveen et al., 2014; Paquet et al., 2004). In the case of our patient, the affected area was between 10 and $30 \%$ of the body surface, which corresponds to the intermediate form. The anatomopathological analysis only showed the typical skin alterations. For example, the skin biopsy revealed a deep necrosis of the epidermis, which was detached from a more or less intact dermis, with a barely noticeable lymphocytic infiltrate. (Paquet et al., 2004). Although bullous toxidermia are frequently reported to have multiple biological attacks (Ho et al. 2010), the assessment performed on our patient revealed only a hyperleukocytosis that mostly involved polynuclear neutrophils. The rapid epidermization coupled with a repigmentation during the treatment, pointed to a rather shallow 
damage to the skin. Such shallow damages heal most often through epidermization from adjacent areas (Barbaud, 2007). As many authors report (Naziha et al., 2010; Barbaud, 2007), the withdrawal of the drug and a detailed letter prohibiting it once and for all should be systematic upon patient discharge. Unfortunately, we could not take these steps given the fact that the patient never came back after a two-week follow-up.

\section{Conclusion}

Toxidermia of the Lyell syndrome type are rarely associated with drugs families. HCQ, used in the treatment of certain so-called autoimmune diseases, has rather variable cutaneous side effects. Despite the rare occurrence of these reactions, it is important to inform the patient to seek medical attention at the slightest effect in the skin or mucous membranes. A medical certificate specifying the drug concerned must be established and given to the patient.

\section{References:}

Assier-Bonnet H, Saada V, Bernier M, Clerici T, Saïag P (1996). Acute Generalized Exanthematous Pustulosis Induced by Hydroxychloroquine. Lett Dermatol; 193:71-72.

Barbaud A (2007). Prise en charge des toxidermies. Ann dermatol Venereol; 134 : 391-401

Bechot N, Roujeau J-C (2000). Imputabilité médicamenteuse en pratique dermatologique. Ann dermatol Venereol; 127: 542-5.

Begaud B, Evreux JC, Janglard J, Lagier G (1985). Imputabilité des effets inattendus et toxiques des médicaments : Actualisation de la méthode utilisée en France. Thérapeutique; 44:111-14.

Bernard Y-H, Tan T-C (2010). Epidemiology and risk factors for drug allergy. Britsh Journal of Pharmacology; 71(5): 684-700.

Ho Y-L, Chang Y-T, Chu Y-T, Wu S-C (2010). Performance of the SCORTEN in Taiwanese patients with Stevens-Johnson Syndrome and toxic epidermal necrolysis. Dermatologica Sinica; 28: 15-20.

Lebrun-Vignes B, Valery-Allanore L (2015). Toxidermies. Rev Med Interne; 36: 256-270.

Metayer I, Balguerie X, Courvillke P, Lauret P, Joly P (2001). Toxidermies photo-induites par I'hydroxychloroquine : 4 cas. Ann dermatol Venereol; 128: 729-31.

Naziha K, Maha B S, Dorsaf M, Mohsen H (2010). Severe Acute Generalized Exanthematous Pustulosis Induced by Hydroxychloroquine Mimicking Toxic Epidermal Necrolysis. Egyt Dermatol O Line; 6(1): 1-7 http://www.edoj.org.eg. 
Paquet P, Flagothier C, Pierard-Franchimont C, Jacob E, Damas P, Heymans $\mathrm{O}$ et al (2004). Les toxidermies paroxystiques graves. Rev Med Liege; 59(5) : 286-292.

Park J-J, Yun S J, Lee J-B, Kim S-J, Won Y H, Lee S-C (2010). A case of Hydroxychloroquine Induced Acute Generalized Exanthematous Pustulosis confirmed by Accidental Oral Provocation. Ann Dermatol; 22(1): 102-105.

Parveen S, Reddenna L, Babu S C, ReddY K N, Rajani R, Kumar E S J et al (2014). Chloroquine Induced Stevens Syndrome: A Case Report. Sch J Med; 2(3): 198-200.

Plaquenil (hydroxychloroquine sulphate) tablets (2006): Adverse reactions. Bridgewater (NJ): Sanofi; Oct 5. Available from: http://www.accessdata.fda.go/drugsatfda_docs/label/2007/009768s0411bl.pd f.

Roujeau J-C, Kelly J-P, Naldi l, Rzant B, Stren Rs, Anderson T et al (1995). Medication use and risk of Stevens-Johnson Syndrome or Toxic epidermal Necrolysis. New England J med; 33(24): 1600-16007.

Schmutz J-L, Barbaud A, Tréchot P. (2008) Dress et hydroxychloroquine. Ann dermatol Venereol; 135, 903.

Studer. M, Waton. J, Bursztejn A.C , Aimone-Gastin I, Schmutz J-L, Barbaud A (2012). La polysensibilisation médicamenteuse existe-t-elle ? Ann dermatol Venereol; 139: 375-380. 